\title{
LA SUBJETIVIDAD NARRATIVA POSMODERNA: PROCESOS DETERMINANTES
}

\author{
MARCOS RocA SIERRA \\ Universidad Complutense de Madrid
}

Sed de realidad.

THOMAS MANN

La construcción y representación de la subjetividad en la narrativa posmoderna viene determinada por la imbricación de cinco procesos que arrancan en las postrimerías de la Modernidad. Estos procesos originan la emergencia de un nueva subjetividad, cuyos rasgos más sobresalientes, que hemos intentado sintetizar en cinco fenómenos, determinan, además, las características más relevantes del sujeto narrativo posmoderno. Los procesos son:

1. En primer lugar, un progresivo desenclave de los parámetros espacio-temporales que ubicaban la identidad del sujeto en las sociedades tradicionales y modernas. El fenómeno del proceso de vaciamiento del espacio y del tiempo en las sociedades modernas socava progresivamente el poder identitario y vinculante de las categorías simbólicas derivadas de dichos parámetros. Desde estas categorías simbólicas se había venido fundamentando, hasta este momento, la identidad de los individuos, y su disolución o vaciamiento ha originado una forma de experimentar la realidad a la que podríamos calificar de «esquizofrénica». En este sentido y a propósito de la vivencia del tiempo en la Posmodernidad, F. Jameson hace una reflexión que nos parece de una gran trascendencia. Su descripción sobre el «tratamiento» temporal se plantea desde la perspectiva de las teorías sobre la esquizofrenia, especialmente la desarrollada por J. Lacan. Con ello no pretende tanto diagnosticar una determinada vivencia temporal como el plantear descriptivamente la manera de experimentar el tiempo en el momento actual apoyándose en este concepto teórico lacaniano. F. Jameson opina que «la originalidad del pensamiento de Lacan a este respecto es haber considerado la esquizofrenia como un desorden del lenguaje y haber unido la experiencia esquizofrénica a toda una nueva visión de la adquisición del

Rlit, LXVII, 134 (2005), 333-348 
lenguaje como el eslabón fundamental que falta en la concepción freudiana de la formación de la psiquis madura ${ }^{1}$. De la concepción estructuralista básica sobre el lenguaje en la que el signo se considera modelado por un significante (que constituye la parte material del mismo) y un significado (el sentido o el concepto al que remite) y del convencimiento de que al escuchar o leer una cláusula entera no nos remite a un significado correlativo (elaborado palabra tras palabra, como una escansión de significados) sino a un «efecto-significado» más global, producido por la interrelación de los significantes materiales, parte la hipótesis que lleva a Lacan a interpretar la esquizofrenia como la «quiebra de la relación entre significantes» ${ }^{2}$. Según F. Jameson, para J. Lacan

\begin{abstract}
la experiencia de la temporalidad, el tiempo humano, el pasado, el presente, la memoria, la persistencia de la identidad personal a lo largo de meses y años, esta sensación existencial o experiencial del tiempo mismo, es también un efecto del lenguaje. Debido a que el lenguaje tiene un pasado y un futuro, a que la frase se mueve en el tiempo, podemos tener lo que nos parece una experiencia de tiempo concreta o vivida. Pero dado que el esquizofrénico no conoce la articulación del lenguaje de ese modo, carece de nuestra experiencia de la continuidad temporal y está condenado a vivir en un presente perpetuo con el que los diversos momentos de su pasado tienen escasa conexión para el que no hay ningún futuro concebible en el horizonte. En otras palabras, la experiencia esquizofrénica es una experiencia de significantes materiales aislados, desconectados, discontinuos que no pueden unirse en una secuencia coherente. Así el esquizofrénico no conoce la identidad personal en el sentido que nosotros le damos, puesto que nuestro sentimiento de identidad depende de nuestro sentido de la persistencia del «yo» a lo largo del tiempo ${ }^{3}$.
\end{abstract}

La percepción del presente, al haberse producido la ruptura de la continuidad temporal, es mucho más intensa y abrumadora al no estar diluida en ningún tipo de proyecto de futuro. Sin embargo, su vivencia del presente también es la del abandono, la de falta de anclaje, en donde no se es «nadie»y se está imposibilitado de acometer ningún tipo de proyecto, ya que esto significaría la superposición de una estructura: la de comprometerse a una unidad a lo largo de un tiempo. La sensación de intensidad realzada de la vida es una suerte de hiperrealidad que se experimenta al mismo tiempo como una «irrealidad». Al nivel del lenguaje, esta ruptura esquizofrénica causa un inusitado encantamiento hacia la materialidad de las palabras, hacia su sonido, que se vuelve obsesivo y se transforma en «un significante que ha perdido su significado (y) se ha convertido así en una imagen» ${ }^{4}$.

\footnotetext{
1 JAMENSON, Frederic (1982), «Posmodernismo y sociedad de consumo» en FOSTER, Hal (ed.) (1988), La posmodernidad. Barcelona, Kairós, p. 176.

2 JAMENSON, Frederic (1982), opus cit., p. 177.

3 JAMENSON, Frederic (1982), opus cit., p. 177.

${ }^{4}$ JAMENSON, Frederic (1982), opus cit., p. 179.
} 
La frecuente aparición en la narrativa actual de una vivencia temporal relacionada estructuralmente con la esquizofrenia (tendencia a sustituir la cronicidad por un tiempo presente de culminación donde confluyen todas las direcciones temporales) tiene inevitablemente su correlato espacial. $\mathrm{La}$ habitual presencia de espacios urbanos, suburbiales, y predominantemente interiores hace llegar a la conclusión a N. Santiáñez de que

\begin{abstract}
la estructuración interiorista de las novelas conlleva una fragmentación de la trama narrativa, y, por ende, de la realidad, cualquiera que sea, que pretende representar. El interior puede ser el mundo de la intimidad del protagonista; también es un emblema privilegiado de un universo autónomo, discontinuo, desordenado. Al limitar o prescindir de la interacción del personaje con el mundo de la calle, la estructura de la novela se presenta menos como un todo panorámico, totalizante y unitario, como es el caso de la mayoría de las obras realistas, que como un conjunto de escenas domésticas no siempre continuas ${ }^{5}$.
\end{abstract}

Esta esquizofrenia temporal tiene su correlato espacial en la tendencia a un espacio interior y estático en la narrativa posmoderna. La dimensión simbólica del espacio interior ya fue puesta de manifiesto por G. Bachelard ${ }^{6}$. En la gran mayoría de la narrativa actual, la interioridad espacial donde se ubica a los personajes está directamente relacionada con la construcción de la subjetividad. En este sentido, N. Santiáñez establece «una íntima relación entre la dominante interiorista de la novela, la presentación de la subjetividad del personaje y el mayor protagonismo del discurso, del lenguaje» ${ }^{7}$.

La frecuente disposición itearitiva del tiempo y la tendencia a la superposición de espacios son una consecuencia de la figuración refleja desde la que se dispone la trama.

2. La mediatización de la experiencia, consecuencia de lo que podríamos denominar la estructura tropológica de la realidad. Se trata de una auténtica «inversión de la realidad» ${ }^{8}$ que se origina al percibir con más conciencia de realidad los sucesos que han sido mediatizados por sistemas de representación que los de la propia experiencia empírica. Sin la mediación de estos sistemas, la realidad aparece devaluada. La conciencia de que la realidad no puede ir más allá de los límites de su representación posibilita que se asimile el estatuto ontológico de la realidad con el de la ficción. Nada escapa a la codificación suplementaria de una estructura tropológica

${ }^{5}$ Cfr. SANTIÁÑEZ, Nil, Investigaciones literarias. Modernidad, historia de la literatura y modernismos, Barcelona, Crítica, 2002.

6 BACHelARD, Gaston (1957), La poética del espacio (trad. E. de Champourcín), México, FCE, 1975, p. 104.

${ }^{7}$ SANTIÁÑEZ, Nil (2002), Investigaciones literarias. Modernidad, historia de la literatura y modernismos, Barcelona, Crítica, p. 319.

${ }^{8}$ GidDENS, Anthony (1991), Modernidad e identidad del yo, Barcelona, Península, 1997, p. 42. 
que impone la experiencia del mundo desde su representación. La aparición de la subjetividad también se originará desde una fenomenología textual a la que podría denominarse textualización del sujeto.

Lo que calificamos de real participa de los mismos mecanismos poiéticos de la ficción. La subjetividad y la ficción se construyen desde las mismas estrategias formales: selección, combinación e invención, tal y como las señala Antonio Muñoz Molina9.

Decir "yo" es ingresar en un orden simbólico que implanta un sentido a la entropía orgánica del yo (estímulos sensoriales, reacciones fisiológicas, psíquicas, percepciones, etc.), el «yo» hace como si implantase un orden marcando un sentido autorreferencial. Para Cuesta Abad: «decir "yo" es ordenarse a uno mismo en el lenguaje, enajenarse en él o ensimismarse en él. Antes del "yo", nada soy para la comprensión; después de él, tampoco. El "yo" es un texto: todo lo que se puede hacer es introducirse en él, penetrarlo de signos y permanecer contemplando un exterior que se pretende interior» ${ }^{10}$. En el mismo sentido G. Bettetini afirma que el sujeto es «un simulacro presente en el texto y casi siempre enmascarado o desplazado en su superficie significante» ${ }^{11}$.

3. La sustitución creciente de una metafísica del la presencia por un principio dialógico de interacción con la alteridad. Su repercusión sobre la constitución del sujeto es determinante. Se produce lo que denomina Cuesta Abad una necesaria complementariedad hermenéutica en la formación de la personalidad del yo, ya que ésta sólo tiene lugar en un posicionamiento dialéctico con respecto a los otros sujetos. No puede construirse una identidad propia prescindiendo de la identidad para-los-otros. Según R. D. Laing, la morfología del sujeto se construye en múltiples procesos de interacción: de una identidad que reconoce para sí, de la identidad que le es atribuida por los otros, de la identidad que el sujeto atribuye a los otros, de lo que piensa que los otros piensan, etc. ${ }^{12}$ Por ello, el sujeto del texto siempre es un sujeto hermenéutico en el sentido de que planea el problema de la comprensión y ésta se realiza en el interior del texto, el lugar en el que el sujeto deviene en ficción al incorporarse al mundo del lenguaje. En este sentido afirma J. Lozano: «Ni la lengua es un sistema unitario ni el sujeto hablante es una entelequia individual dada a priori de su práctica

\footnotetext{
${ }^{9}$ Cfr. MuÑoz MolinA, Antonio (1993), La realidad de la ficción, Sevilla, Renacimiento. Y MUÑOZ MolinA, Antonio (1998), Pura alegría, Madrid, Alfaguara.

${ }^{10}$ Cuesta ABAD, José Manuel (1991), Teoría hermenéutica y literatura (El sujeto del texto), Madrid, Visor, p. 236.

11 Bettetini, Gianfranco (1987), «El giro pragmático en las semióticas de la representación» en VV.AA (1987), La crisis de la literariedad, Madrid, Taurus, p. 164.

${ }_{12}$ Puede verse LAING, R. D. (1961), El yo y los otros, México, FCE, 1974. Estas ideas están desarrolladas en la tercera parte de este estudio.
} 
discursiva. El discurso es el lugar de construcción del sujeto» ${ }^{13}$. Por ello, para Cuesta Abad, «la realidad primera - y en cierto modo la última- de la obra literaria consiste en modelar estéticamente los universales antropológicos de la autocomprensión y heterocomprensión haciendo uso de la inmensa variedad de posibilidades de que dispone el lenguaje» ${ }^{14}$. El sujeto es «un sistema dinámico de unidades culturales que se configuran semióticamente. En el interior del texto el sujeto se hace cultura (adviene en la forja de un yo) porque sólo así puede incorporarse a la semiosis» ${ }^{15}$.

La irrenunciable alteridad, la necesaria presencia de los otros en la constitución de la subjetividad y en la formación de la identidad fue ya formulada por Heidegger en Ser y Tiempo como resume Cuesta Abad: «En la hermenéutica heideggeriana la noción de "los otros" no significa lo mismo que la totalidad de los demás fuera de mí de la que sobresale el yo, sino más bien aquellos de los que ordinariamente no se distingue uno mismo, entre los que éste es también uno». El "ser con" (Mitsein) alude a un rasgo sustantivo del sujeto humano que se proyecta hermenéuticamente: «El "estado abierto" del "ser ahí con" de otros, estado inherente al "ser con", quiere decir: en la comprensión del ser que es inherente al "ser ahî" está implícita, por ser el ser del "ser ahî" un "ser con", la comprensión de los otros» ${ }^{16}$.

Es oportuno reseñar las dos teorías que a nuestro juicio mejor ejemplifican la necesaria disposición dialógica de la subjetividad posmoderna: la formulada por R. D. Laing y la de Carlos Castilla del Pino.

La pretensión de R. D. Laing es la de construir una teoría de la esquizofrenia desde el punto de vista de la psiquiatría fenomenológico-existencial ${ }^{17}$. Sin embargo, este empeño teórico se enmarca en un territorio más abarcador ya que lo que realmente está analizando son los procesos de interacción que nos permiten comprendernos como identidades personales. Del análisis que desarrolla R. D. Laing nos interesan tres conceptos teóricos fundamentales: la complementariedad, la elusión y la colusión.

Podríamos sintetizar su teoría mediante el siguiente planteamiento: el requisito básico para la adquisición de la identidad personal es la complementariedad. Esta función se entiende como la necesidad ineludible de lo otro (o de "un otro") para que pueda completarse el proceso autocognitivo. La estructura diádica de la complementaridad se despliega en dos formas

\footnotetext{
${ }^{13}$ LozAno, Jorge, Cristina PeÑa-Marín y Gonzalo ABril (1999), Análisis del discurso. Hacia una semiótica de la interacción textual, Madrid, Cátedra, p. 89.

14 Cuesta ABAD, José Manuel (1991), opus cit., p. 240.

15 Cuesta ABAD, José Manuel (1991), opus cit., p. 239.

16 Cuesta ABAD, José Manuel (1991), opus cit., p. 238.

17 Vid. LaInG, R. D. (1960), El yo dividido, México, Fondo de Cultura Económica,
} 1964. 
básicas: la elusión (proceso donde solamente está implicado un sujeto) y la colusión (proceso donde están implicados dos o más sujetos).

Laing define la complementariedad como aquella función de las relaciones entre los sujetos por la que se satisface o llega a su identidad el Yo:

La "propia" identidad de una persona no puede abstraerse por completo de su identidad-para-otros. Su identidad-para-sí; la identidad que otros le adscriben; las identidades que ella les atribuye a éstos; la identidad o identidades que piensa que ellos le atribuyen; lo que piensa que ellos piensan que ella piensa que ellos piensan...

La «identidad» es aquello por lo que uno siente que es el mismo, en este lugar y este tiempo, tal como en aquel tiempo y en aquel lugar pasados o futuros; es aquello por lo cual se es identificado. Tengo la impresión de que en su mayoría las personas tienden a creer que son las mismas, en continuidad desde el vientre materno hasta la tumba; y que mientras más se fantasea esta identidad, más intensamente se la defiende ${ }^{18}$.

La identidad como el resultado de un proceso de desplazamientos, de juegos o apariencias, puede encauzarse desde los dos procedimientos antes aludidos: la elusión y la colusión.

La elusión, es una maniobra que consiste en rodear el conflicto de la identidad sin afrontarlo de una manera directa a partir de un proceso de doble fingimiento por parte del sujeto, provocando así su desdoblamiento: «La elusión es una relación en la que se finge uno a sí mismo que se aleja del propio YO original; después, se finge que se regresa de este fingimiento de suerte que parezca que se ha llegado de nuevo al punto de partida. Un doble fingimiento simula no ser fingimiento» ${ }^{19}$. Con la elusión, el tiempo llega a convertirse en una experiencia vacía ya que se vive fuera de su dominio. Todos estos rasgos estructurales de la elusión son recurrentes, aunque no exclusivos, de la esquizofrenia. La identidad colusiva, al contrario de la identidad elusional, se adquiere gracias a la confirmación del otro, que entra necesariamente en el mismo juego, a veces sin tomar ninguna conciencia de ello.

La colusión (del latín collusio) pertenece al campo semántico de raíz latina ludere, que significa tanto jugar, como mofarse o engañar. Lo que la diferencia del delirio es que éste implica un autoengaño total (y lo mismo sucede con la versión atenuada del delirio: la ilusión). Para Laing «la colusión (...) tiene resonancias de jugar a algo y de engañar. En un «juego» que es el juego del autoengaño mutuo. Mientras podemos hablar de delirio, ilusión y elusión respecto de una sola persona, la colusión es necesariamente un juego entre dos o más» ${ }^{20}$. Laing afirma que «la colusión del

${ }^{18}$ LAING, R. D. (1961), El yo y los otros, México, Fondo de Cultura Económica, 1974 , p. 82.

${ }^{19}$ LAING, R. D. (1961), op. cit., pp. 43-44.

${ }^{20}$ LAING, R. D. (1961), op. cit., p. 103. 
otro es necesaria para «complementar» la identidad que el YO se siente impelido a mantener (...). Cada YO ha encontrado, así, un otro para ratificar su propia noción falsa de sí y para darle un parecido de realidad a esta apariencia ${ }^{21}$. La colusión puede darse también en cualquier tipo de situación interaccional básica puesto que, de la misma manera, se basa fundamentalmente en el mismo juego de apariencias.

Realmente esta dinámica de desplazamientos, juegos y confirmaciones está en la base de toda interacción humana que, a su vez, es la que posibilita la ilusión de la identidad. La identidad del sujeto en la ficción narrativa descansa sobre estos mismos procesos de desplazamientos y autoinvenciones. Todo el juego de apariencias puede resumirse en formas adquiridas a partir de procesos de elusión y colusión. Por este motivo consideramos estos dos procesos como las matrices relacionales de todas las interacciones posibles.

La consecuencia fundamental es que todo proceso de autoinvención o de interacción con los demás lleva implícita una prefiguración que adopta la forma de desplazamiento (también en el sentido de a-plazamiento), de desdoblamiento (en el caso de la elusión) o diseminación (en el caso de la colusión), en espera de su figuración como sujetos dotados de una identidad. La elusión y la colusión son estrategias de ficcionalización que parten de una misma condición de posibilidad: la necesaria estructura diádica del sujeto en un entramado de apariencias. La exotopía que produce la elusión es un correlato de lo que en la colusión corresponde al «otro»: la estructura exotópica es idéntica en ambos casos. El interés de la teoría de Laing es que parte del presupuesto de que esa condición exotópica de desdoblamiento del sujeto es inherente a todo proceso de cognición subjetiva y no solamente al que se dirime en la ficción literaria.

Creemos que otra de las mejores y más completas caracterizaciones de la subjetividad desde el punto de vista relacional (interacción dialógica) e identitario es la que lleva a cabo Carlos Castilla del Pino. Es en el capítulo «La construcción del self y la sobreconstrucción del personaje» perteneciente a una compilación sobre la Teoría del personaje realizada por él mis$\mathrm{mo}^{22}$, donde esboza lo que será el primer acercamiento a una teoría sobre la identidad mucho más elaborada a la que haremos referencia más adelante. Creemos oportuno y esclarecedor sintetizar esta teoría ya que la consideramos una de las más rigurosas y sistemáticas de las realizadas hasta el momento. Sobre todo con la publicación de Teoría de los sentimientos ${ }^{23}$ que es donde Castilla del Pino profundiza y formula su teoría sobre el sujeto más ambiciosa.

\footnotetext{
${ }^{21}$ LAING, R. D. (1961), op. cit., pp. 106-107.

${ }^{22}$ Castilla del Pino, Carlos (1989), Teoría del personaje, Madrid, Alianza Editorial.

${ }^{23}$ Castilla del Pino, Carlos (2000), Teoría de los sentimientos, Barcelona, Tusquets.
} 
El planteamiento e interés por el sujeto desde la psiquiatría es justificado por Castilla del Pino porque «introducir el sujeto con criterios de cientificidad supone un nuevo paradigma de alcances insospechados para la psicología, la piscopatología y la psiquiatría clínica» ${ }^{24}$. Denomina sujeto al «sistema desde el cual el Yo se organiza y construye, en el que se almacena los yoes organizados, y desde donde se prepara para la actuación con uno de ellos ${ }^{25}$. El sujeto es uno de los muchos sistemas del organismo humano que intenta adaptarse al entorno simbólico-psicosocial, lo mismo que los otros sistemas intentan adaptarse al medio (fisicoquímico). Como tal sistema está dotado de una enorme versatilidad, «los yoes que dispone son módulos que remedan al sujeto adoptando la forma de un Yo para la actuación. El sujeto es un conjunto de n-yoes, a) actuales: empíricos, imaginados o fantaseados; b) pretéritos, susceptibles de ser evocados y actualizados; y c) futuros, anticipados o prolépticos, a modo de ensayos de actuación:

$$
S(Y) n »^{26}
$$

La relación con la realidad es el gran problema que hay que resolver (ajustarse al que Freud llamaba principio de realidad). Es un problema de una doble dimensión, por un lado cognitivo y, por otro, emocional. Las actuaciones del Yo son respuestas a la presencia del objeto y tienen como objetivo su adecuación. En cada actuación, además, se infiere la teoría que el sujeto posee acerca del objeto. El yo resulta ser, pues, una construcción pragmática del sujeto. La fórmula que resume la teoría de Castilla del Pino acerca del sujeto es la siguiente:

\section{$f[S($ Y/imObp) $] C x$}

Donde $f$ es el functor modificador de las distintas modalidades de actuaciones emocionales (amar, simpatizar, entristecerse, etc.) en las que el sujeto actúa como un Yo ante la imagen (im) parcial (p) que tenemos de un objeto $(\mathrm{Ob})$ en un contexto determinado $(\mathrm{Cx})$. El sujeto construye ese Yo como respuesta / propuesta al objeto, el Yo más adecuado a cada tipo de modalizador $f$.

El Yo de cada acción es parte del sujeto, es una imagen que el sujeto tiene de sí mismo adecuada para ese contexto y para la interacción con el objeto. Podría decirse entonces que toda interacción con alguien es siempre una relación parcial e imaginaria entre ambos Yoes. «La interacción no es una relación de sujeto a sujeto, sino del Yo de uno con el Yo que el

\footnotetext{
24 Castilla del Pino, Carlos (2000), op. cit., p. 37.

25 CASTIlla DEL PINO, Carlos (2000), op. cit., p. 40.

${ }^{26}$ CAstilla Del Pino, Carlos (2000), op. cit., p. 41.
} 
otro se ve obligado a construir» ${ }^{27}$. Por consiguiente, la relación Sujeto/Objeto es doblemente ilusoria. La interacción está afectada de una doble falacia que Del Pino califica de metonímica (al confundir la parcialidad del Yo con el todo) y objetivista, al considerar esa relación imaginaria con lo real, identificando parecer con ser.

El sujeto no es nunca neutro: es un sistema relacionante y su actividad y su tendencia a la anhomeostasis (desequilibrio) no cesa. Sus problemas pueden reducirse a dos: la necesidad de establecer vínculos con determinados objetos para satisfacer sus deseos, y el hacer esto con el menor coste posible. Es pues, un sistema para la resolución del conflicto cognitivoemocional que es toda relación sujeto/objeto. Si el conflicto $f$ [ $S$ (Y/imObp)] $C x$ se resuelve favorablemente, la anhomeostasis, o desesequilibrio inicial, se repara para dejar paso a una homeostasis interna (del sujeto consigo mismo) y externa (con relación al objẹto).

Podríamos afirmar que es éste precisamente el tema más redundante en la narrativa de las últimas décadas: el dar una respuesta desde la literatura a la resolución del conflicto cognitivoemocional que provoca el conflicto del individuo con la realidad.

4. El cuarto proceso es también una consecuencia derivada de la devaluación progresiva del valor constructor de las categorías identitarias simbólicas: la constatación de una creciente reflexividad como mecanismo constructor de la identidad.

Sobre este asunto, la tesis fundamental de A. Giddens ${ }^{28}$ supone la constatación de la aparición de unos nuevos mecanismos para la construcción de la identidad del yo a partir del advenimiento de la Modernidad (término que define como orden postradicional), una vez que se han ido transformando las estructuras organizativas de la sociedad tradicional, fenómeno especialmente constatable en el momento actual al que prefiere denominar Modernidad reciente. Las nuevas formas constructivas de la identidad se encuentran en un constante proceso de modulación e interacción con las nuevas instituciones de la Modernidad. Para Giddens la estructura fundamental de organización de cualquier institución o instancia de la realidad moderna viene determinada por la reflexividad, concepto que desarrollamos a continuación.

A partir de la generalización desde la Modernidad de los mecanismos de desenclave o sistemas abstractos se ha producido un vaciamiento progresivo del espacio y el tiempo en su sentido tradicional y se ha ido modelando una forma de organización que afecta a todos los niveles de la realidad: los sistemas de referencialidad interna. En el amplio espectro de

\footnotetext{
27 Castilla del Pino, Carlos (2000), opus cit., p. 42.

${ }^{28}$ Cfr. GidDENS, Anthony (1991), op. cit.
} 
estos sistemas reflejos internamente referenciales está incluido el proyecto reflejo del yo que puede interpretarse como la identidad adquirida por el ordenamiento o el mantenimiento de una crónica personal con un sentido coherente. Giddens opina que actualmente «la expansión de los sistemas internamente referenciales alcanza sus límites extremos; en el plano colectivo y en la vida de cada día, las cuestiones morales/existenciales pasan a ocupar una posición central» ${ }^{29}$.

Las consecuencias de los mecanismos de desenclave sobre la identidad del yo tienen una repercusión directa en el ámbito espacio-temporal de los sujetos. El tiempo de la vida se separa del ciclo vital de la sucesión de las generaciones característico de la época tradicional. Igualmente, hay una separación o vaciamiento del espacio que empieza a adquirir desde este momento un carácter fantasmagórico al estar igualmente bajo el influjo de los mecanismos de desenclave. El espacio ya no es verificable como parámetro de la experiencia y ha perdido su carácter significador como referente externo para la construcción de la identidad del individuo.

Otro tanto sucede con el vínculo identitario que proporcionaban los otros individuos o grupos, especialmente los que detentan un mayor grado de relación (estirpe, lazos parentales, matrimonio) al ir sustituyéndose este tipo de relación vinculativa por lo que Giddens denomina relaciones puras. La relación pura es uno de los entornos para la construcción del proyecto reflejo del yo. Una relación pura es aquella relación internamente referencial la cual no está basada más que en la gratificación que proporciona una interacción que no está sujeta a ningún factor externo más allá que el de la propia relación.

En cualquier caso, los mecanismos de desenclave no vacían por completo los apoyos en los que se basaba la identidad tradicional sino que más bien proveen al yo de unas nuevas perspectivas sobre las que forjar la identidad a partir del nuevo dominio de la referencialidad interna.

Puede afirmarse que los sistemas abstractos (divididos por Giddens en sistemas expertos y en señales simbólicas) vacían la vida en su sentido tradicional socabando el sentimiento de seguridad ontológica en la que se basaba y ejerciendo, además, una poderosa globalización de la experiencia. El sentimiento de seguridad ontológica en las sociedades tradicionales venía otorgado por los atributos conformadores de la identidad (el linaje, etc.), establecidos de una manera fija y marcados y significados por los llamados ritos de paso. Estos ritos ponían a las personas en contacto con fuerzas cósmicas que otorgaban un sentido a la existencia de los individuos al vincularlas con marcas morales o existenciales exteriores a su yo. La tradición y sus formas rituales van perdiendo poco a poco su sentido a medida que la reflexividad va penetrando en el corazón de la vida diaria.

${ }^{29}$ GidDENS, Anthony (1991), Op. cit., p. 263. 
El nuevo marco de seguridad ontológica de la Modernidad reciente es, pues, mucho más débil. Giddens denomina «secuestro de la experiencia» a las condiciones para el establecimiento de áreas de seguridad relativa de las que se sirve la Modernidad. Su pretensión es la de reprimir y ocultar los componentes existenciales básicos para la vida (la sexualidad, la enfermedad y la muerte, la locura, la criminalidad y la naturaleza) y ofrecer de todo ello una experiencia mediada y conseguir de este modo un sentimiento de seguridad básica que adopta formas de rutina susceptibles de ser vividas como unas meras prácticas vacías.

La identidad del sujeto, pues, queda relegada principalmente al establecimiento de una crónica coherente de la identidad del yo.

Este proceso que acabamos de describir tiene su correspondiente repercusión en las estructuras diegéticas de la narrativa actual donde el sujeto queda construido a partir de sistemas internamente referenciales. Podríamos distinguir desde esta perspectiva entre dos tipos de sistemas identitarios:

I. Sistemas identitarios de referencialidad externa elaborados a partir de categorías de identificación simbólica. Estos sistemas están caracterizados por producir estructuras diegéticas con resolución teleológica fundamentadas en la pérdida/recuperación por parte del sujeto de esas mismas categorías. Y,

II. Sistemas identitarios de referencialidad interna construidos a partir de categorías internamente referenciales de identificación imaginaria o refleja. Los modos de referencialidad interna están caracterizados por la reflexividad.

5. Y en último lugar, lo que puede denominarse la emergencia de una nueva centralidad del sujeto. El principio antrópico ejemplifica, a manera de metáfora científica, la necesidad de una disposición subjetiva como condición de posibilidad para cualquier proceso de cognición. De igual forma, la historia del relato tiende a subjetivizarse, parece como si el valor de la historia relatada dependiera de la vivencia subjetiva de la misma. La historia que se nos cuenta es tal en tanto es la historia experimentada por un determinado sujeto y ésta cambiaría sustancialmente si desplazáramos el punto de focalización desde el que la percibimos.

Tras el advenimiento de la Mecánica Cuántica (teoría física que describe el comportamiento de los sistemas físicos del átomo y el mundo subatómico), el indeterminismo y la incertidumbre que afectaban al conocimiento de las partículas más elementales entran en conflicto con los postulados básicos de la Física clásica, que se fundamentaba en la operatividad universal de un determinado número de leyes y modelos teóricos. Se asiste así a una radical transformación del carácter de las leyes físicas que dejan de ser deterministas para transformarse en probabilistas. 
Esta situación le lleva a plantearse al físico John Wheeler que la realidad no es un fenómeno físico puro, sino que emerge como un acto intencional de la observación, definiéndola como una «entidad participada» ${ }^{30}$. La realidad no existiría fuera de su condición de «acto participado» por el sujeto observador. El observador deja de ser una figura impersonal e independiente para adquirir una relevancia decisiva para la existencia del fenómeno que estudia. Las leyes físicas se consideran como un acto inseparable del resultado ineludible entre la conciencia y el mundo. El físico no sería tan sólo un observador, sino un «participante» que con su observación otorga existencia a lo que explora. Esta interpretación puede ser considerada como una versión «participatoria» del principio antrópico que sitúa en una posición central el subjetivismo del observador.

Una de las evidencias de la crisis del paradigma de la Física clásica, es el cambio teórico producido en el terreno de la Cosmología. En la Cosmología científica tradicional, el ser humano era considerado como una realidad casi innecesaria en la evolución de la materia, y la conciencia como un resultado de una estructuración compleja de la misma. Ha sido durante las últimas tres décadas cuando se han abordado las condiciones iniciales en Cosmología en términos de condiciones necesarias para posibilitar la vida. El simple hecho de nuestra existencia ha limitado las posibilidades que deben considerarse. Se empieza a tomar conciencia de la inteligibilidad del universo desde parámetros evolucionistas debido precisamente a la extrema rareza en las múltiples condiciones necesarias para que surja un mundo como el nuestro. Steven Weinberg condensó esta conclusión en una frase que ha sido replicada en multitud de ocasiones por científicos y filósofos:

Cuanto más comprensible parece el universo, tanto más sin sentido parece también ${ }^{31}$.

En 1974, Brandon Carter formula el llamado principio antrópico. El éxito de este concepto, y sobre todo, la extrapolación del mismo a otras áreas del saber, se debe principalmente a su operatividad y a la capacidad heurística del mismo. Existen dos formulaciones fundamentales del principio antrópico, aunque ninguna de ellas presenta alguna novedad, ya que en esencia, se puede rastrear este principio desde el pensamiento aristotélico. La idea básica de la versión débil (PAD), es que «la evolución ha tenido lugar tal y como la ciencia nos sugiere, pero (...) el impulso inicial, contenido en las leyes básicas de la física que permiten una tal evolución, tie-

${ }^{30}$ WHEELER, John A. (1981), «¿Qué es la realidad?» en Investigación y Ciencia, n. ${ }^{\circ}$ 178, julio, 1981, pp. 36-37.

31 WEINGER, Steven (1977), Los tres primeros minutos del universo, Madrid, Alianza, 1978 
ne un carácter finalista; justamente el que en algún momento del proceso evolutivo aparezca la especie humana» ${ }^{32}$. B. Carter lo formula de este modo:

Nuestra localización en el universo es necesariamente privilegiada, en la medida en que tiene que ser compatible con nuestra existencia como observadores ${ }^{33}$.

Dicho de otra forma, las condiciones de la existencia de algo son posibles por el simple hecho de poder constatarlas. ¿No podríamos considerar esta teoría, en su versión débil, como una reformulación muy aproximada al Cogito ergo sum cartesiano? Si en algo se diferencian en su formulación es en la insistencia en el principio antrópico de interiorizar al observador en el mismo hecho de la observación y producir así una objetivación del sujeto.

La versión del principio antrópico fuerte (PAF) supone la constatación de una teleología, ya que se reconocería una orientación, un designio cósmico que haría posible la vida y la conciencia ${ }^{34}$.

Por otra parte, en un estudio sobre investigación social, el sociólogo Jesús Ibáñez llega incluso a justificar la existencia de este sujeto reflexivo a partir de la física que lo origina:

El sujeto - «absoluto», «relativo»— se ha desvanecido: sólo queda la posibilidad de un sujeto «reflexivo». Son las tres posiciones del sujeto en física: clásica, relativista y cuántica. El sujeto es interior a la representación, que es interior a lo representado ${ }^{35}$.

Añade además una sugerente interpretación sobre una nueva forma de centralidad desde la que se configura el sujeto:

Después del descentramiento del sujeto (Copérnico, Darwin, Freud), un nuevo centramiento (principio antrópico). No soy una anomalía en los márgenes,

${ }^{32}$ LÓPEZ, Cayetano (1999), «Retorno al antropocentrismo. A propósito del Principio Antrópico», en Claves de razón práctica, Madrid, octubre, p. 30.

${ }^{33}$ CARTER, Brandon (1974): «Large Number Coincidences and the Anthropic Principe in Cosmology», en M. S. LONGAIR (ed.), Confrontation of cosmological theories with observational data. IAU Symposium No. 63; D. Reidel Publishing Company and Dordrecht-Holland.

${ }^{34}$ Los físicos John Gribbin y Martin Rees, de la Universidad de Sussex (Inglaterra) proponen un ejemplo didáctico para entender la diferencia entre ambas versiones. Si un individuo se sitúa frente a un pelotón de fusilamiento de cincuenta soldados y después de haber oído la descarga continúa vivo, pueden darse dos respuestas al hecho de por qué aún continúa vivo. La primera respuesta, que correspondería al pincipio antrópico débil sería: Estoy vivo porque puedo saber que los soldados han fallado casualmente sus disparos. La segunda respuesta posible, que correspondería al principio antrópico fuerte, sería: algo ha debido influir para que los soldados deliberadamente fallasen el disparo ya que las probabilidades de salir con vida eran casi nulas.

${ }^{35}$ IBÁÑEZ, Jesús (1994), El regreso del sujeto. La investigación social de segundo orden, Madrid, Siglo XXI, p. 72. 
soy un dispositivo de reflexividad que el universo se pone en su centro. El universo es como es porque yo soy como soy $^{36}$.

Del antropocentrismo del principio antrópico deriva un modelo de subjetividad que, siguiendo a J. Ibáñez, podríamos denominar subjetividad antrópica, ya que participaría de los mismos rasgos estructurales de dicho principio. Podríamos resumirlos en tres peculiaridades que, para nuestro propósito, podríamos formular en los siguientes términos:

1. Centralidad del sujeto (pero a la vez desenclave del sujeto por la multiplicidad de sus ubicaciones posibles).

2. Interioridad del sujeto (determinado por su posicionamiento reflejo).

3. Retroacción (consecuencia de una consideración teleológica donde parecen invertidos los términos causa/efecto).

Podríamos aunar estas tres ideas en el intento de una definición posible sobre lo que podríamos denominar subjetividad antrópica, de tal manera que en dicha definición estén presente el quién, el dónde y el cómo que representan las tres características señaladas. Denominaremos, pues, subjetividad antrópica a un dispositivo cognitivo de focalización refleja.

Carente del ordenamiento exterior que proporcionaría la existencia de un fundamento simbólico, el mundo sólo es posible con la incorporación, en su momento de aprehensión, del sujeto que lo contempla. El sujeto se ha convertido en la comprensión y el ordenamiento de la entropía que supone la vida. El mundo cobra sentido en el momento en que el sujeto adquiere conciencia de ser, o mejor dicho, un «saberse estar siendo» como diría Américo Castro ${ }^{37}$.

La indagación en la incertidumbre de saberse despojado de un sentido se resuelve desde la centralidad que supone el proceso de subjetivización de la realidad. Podríamos afirmar que asistimos a una subjetivización del espacio y del tiempo ya que han dejado de ser considerados categorías referenciales externas. Su percepción parece filtrarse desde la mediación vivencial subjetiva de las mismas.

Las tramas de la subjetividad, como estrategias narrativas para la construcción del sujeto se han convertido en la mediación necesaria para la consecución del sentido. Una de las repercusiones de subjetivizar esta realidad empleando sistemas internamente referenciales es la abolición del tiempo cronológico en su sentido teleológico o dramático. La vivencia temporal que se realiza desde la centralidad del sujeto da lugar a un tiempo vivido como culminación y cumplimiento. La disposición iterativa del tiempo y la tendencia a la superposición de espacios son consecuencia de esta disposición refleja.

\footnotetext{
${ }^{36}$ IBÁÑEZ, Jesús (1994), op. cit., p. 73.

${ }^{37}$ Cfr. CASTRO, Américo (1967): «La estructura del Quijote», en Hacia Cervantes, Madrid, Taurus, pp. 321 y ss.
} 
En los relatos posmodernos (en el sentido amplio del término, ya que en él incluiríamos toda la variedad de formas artísticas posibles como la narrativa, el cine, el teatro, etc.), la disposición de los hechos narrados se mediatiza desde una centralidad subjetiva que tiende a focalizar la historia con el objeto de conseguir una transfiguración del sujeto: desde su relatarse el sujeto deviene en realidad.

Los cinco procesos señalados (la aparición de la vivencia esquizofrénica de la realidad como consecuencia del vaciamiento espacio-temporal; la creciente mediatización de la experiencia que origina lo que hemos llamado una estructura tropológica de lo real; la crisis de la «metafísica de la presencia» y su sustitución por una necesaria disposición dialógica en la construcción de los sujetos; la devaluación progresiva de las categorías simbólicas en la construcción de la identidad y el surgimiento de sistemas internamente referenciales; y, por último, la centralidad e introspección del sujeto en la interpretación de la realidad) determinan la construcción del sujeto posmoderno como un acto consciente de ficcionalización narrativa, entendida ésta como un proceso discursivo y reflejo de construcción de la subjetividad $^{38}$. 


\title{
RESUMEN
}

La subjetividad posmoderna: procesos determinantes, Por Marcos Roca Sierra

Entre los procesos más relevantes en la aparición de la subjetividad posmoderna, cinco son, a juicio del autor, los que determinan la construcción del sujeto como un acto consciente de ficcionalización narrativa, entendida ésta como un proceso discursivo y reflejo. Los procesos son los siguientes: la vivencia «esquizofrénica» de la realidad como resultado de un vaciamiento del significado de los parámetros espacio-temporales; la creciente mediatización de la experiencia que origina lo que podríamos denominar una estructura tropológica de lo real; la crisis de la «metafísica de la presencia» y su sustitución por una necesaria disposición dialógica en la construcción de los sujetos; la devaluación progresiva de las categorías simbólicas en la construcción de la identidad y el surgimiento de sistemas internamente referenciales; $\mathrm{y}$, por último, la centralidad e introspección del sujeto en la interpretación de la realidad.

Palabras clave: Sujeto, subjetiviidad posmoderna.

\begin{abstract}
Among the most relevant processes in the occurrence appearance of post modern subjectivity, there are five, in the judgement of the author, which determine the construction of the subject as a conscious act of narrative fictionalization, the latter being understood as a discoursed and reflexive practice. The processes are the following: The «schizophrenic» experience of reality as a result of the absence of meaning within the space-time parameters; the growing determination of the experience which causes what we could denominate as a tropological structure of reality; the crisis of the «metaphysics of presence» and its substitution for a necessary dialogical arrangement disposition in the construction of subjects; the progressive devaluation of symbolic categories in the construction of identity and the appearance of internally referential systems; and, finally, the centring and introspection of the subject in the interpretation of reality.
\end{abstract}

Keywords: Subject, post modern subjectivity. 